\title{
Understanding of bat wing evolution takes flight
}

\author{
Kimberly L. Cooper and Clifford J. Tabin ${ }^{1}$ \\ Department of Genetics, Harvard Medical School, Boston, Massachusetts 02115, USA
}

It has long been debated whether the processes and mechanisms responsible for phenotypic variation within a population or between closely related populations can be extrapolated to explain evolutionary trends over longer phylogenetic distances and especially the generation of novel structures. Although there has been great progress in recent years in addressing the genetic basis for microevolutionary changes, for the most part these efforts have done little to address this debate. Evolutionary genetic studies, by their nature, can only be applied to closely related groups. For example, quantitative trait mapping is limited to species with distinct morphological traits that are capable of producing viable progeny when crossed either naturally or artificially. There are only a few cases in which linkage mapping has thus far been applied even at the distance of interspecific hybrids to identify loci responsible for morphological differences between highly related species (Sucena et al. 2003; Shapiro et al. 2004; Colosimo et al. 2005; Kronforst et al. 2006; Protas et al. 2006; McGregor et al. 2007). While the genomes of more distantly related taxa can be compared, the effect of molecular drift over millions of years has generated a large noise of sequence variation that makes the identification of specific and functionally relevant changes analogous to finding a needle in a haystack. In this issue of Genes \& Development, Cretekos et al. (2008) have found one such needle-an enhancer of the paired-box homeodomain transcription factor, Prx1, that accounts for at least part of the extension of the long bones in the wings of bats.

\section{Bat bone biology}

The Order Chiroptera, comprised of all bats, makes up a significant percentage of extant mammals, indicating the evolutionary success of their unique and defining trait, the acquisition of powered flight. Key to this adaptation is the morphological evolution of the bat's wing, a highly modified tetrapod limb structure. Several morphological changes were required to derive the bat wing from its ancestral form, including increasing the mem-

${ }^{1}$ Corresponding author.

E-MAIL tabin@genetics.med.harvard.edu; FAX (617) 432-7595.

Article is online at http://www.genesdev.org/cgi/doi/10.1101/gad.1639108. brane surface area between the digits and between the forelimb and flank, reducing thickness of cortical bone to decrease weight and torsional stresses (Swartz et al. 1992), increasing the strength and mass of anterior forelimb muscles (Thewissen and Babcock 1992), and rerouting innervation to control powered flight (Thewissen and Babcock 1991). In addition, the ability of the bat's wing to provide sufficient lift for flight requires the increased length of skeletal elements relative to ancestral forelimbs.

Based on morphological analysis, much of the great difference in the length of the forelimb skeleton in bats relative to similarly sized mice can be attributed to a greater elongation of skeletal elements after their initial primorida are formed. Cretekos et al. (2008) have taken a candidate approach to investigate the role of $\operatorname{Prx} 1$ in allometric elongation of forelimb skeletal elements in the bat species Carollia perspicillata. Prx1 encodes a transcription factor that, in mice, has been implicated as a key regulator of long bone elongation during $\operatorname{limb}$ growth (Martin et al. 1995). By in situ hybridization comparison of endogenous mRNA expression patterns in similarly staged bats and mice, Cretekos et al. (2008) conclude that Prx1 is up-regulated in the cartilage and perichondrium of distal limb in bats, indicating that a modification in the regulation of this gene may have contributed to the morphological specialization of the bat forelimb.

Based on an orthologous sequence in mice (Martin and Olson 2000), Cretekos et al. (2008) identified a highly conserved enhancer element located upstream of Prx1 that is sufficient to drive lacZ expression in limbs of reporter transgenic mice. When this sequence originates from the bat, reporter expression is up-regulated more distally in transgenic mice compared with the expression seen when the reporter is driven from the homologous mouse sequence, consistent with the species-specific differences observed in endogenous Prx1 expression. When knocked into the homologous location of the mouse genome, the same fragment of bat DNA results in a small but nonetheless statistically significant increase in limb length from late developmental stages until birth. This increase is correlated with up-regulation of Prx1 expression in the perichondrium and increased chondrocyte proliferation. These experiments were con- 
ducted such that the only difference between the mouse lines, other than the stretch of bat sequence, is a single loxP site. Because all experiments are compared with control mice with the single loxP site, the observed differences can be rigorously attributed to the trans-species replacement of this enhancer sequence.

Strikingly, deletion of the homologous enhancer sequence in mice results in offspring with no significant difference in limb lengths, suggesting that while $\operatorname{Prx} 1$ is required for limb bone growth (Martin et al. 1995), this specific enhancer is not required in mice. This may be explained by redundancy in the regulatory elements responsible for driving endogenous Prx1 expression in mouse limbs. However, the phenotypic effect in bats appears to be due to a gain of function for this enhancer since endogenous bat Prx1 and lacZ driven from the bat reporter construct in mice are increased and prolonged in distal aspects of the limb and in the perichondrium. Therefore, the ideal experiment would be to knock this enhancer out of the bat and observe the resulting phenotype, an experiment that, given today's technology, is not feasible but may be possible in the future with the advent of recent methodologies such as RNAi.

An important unanswered question is how these differences in Prx1 expression mediate their effect on skeletal elongation. Endochondral long bones develop by the mineralized replacement of a cartilage scaffold that forms from condensed mesenchymal cells in the early developing limb bud. During chondrogenic growth, cells are organized so that a resting zone of slowly proliferating chondrocytes is located at the ends of the developing skeletal element. Cells from the medial end of the resting zone increase their rate of cell division and enter the proliferative zone, where they organize into stacks of rapidly dividing cells. As proliferating chondrocytes reach the end of the proliferative zone, they stop dividing, undergo hypertrophy, and subsequently die by apoptosis. As the cells undergo hypertrophic differentiation, they change the nature of the extracellular matrix, induce the membrane that ensheathes the skeletal element, the perichondrium, to produce osteoblasts, and recruit vasculature, osteoblasts, and osteoclasts to the newly forming bone (for review, see Kronenberg 2003).

Chondrocyte proliferation and differentiation are under complex regulation by a large number of signaling pathway components such as bone morphogenetic proteins (Bmps), fibroblast growth factors (Fgfs), insulin-like growth factors (Igfs), Wnts, Indian hedgehog (Ihh), parathyroid hormone-related protein (PTHrP), retinoids, and circulating factors such as vitamin $\mathrm{D}$, estrogen, thyroid hormone, and glucocorticoids. While little is known of the molecular function of Prxl in the developing skeleton, the observations from this work, paired with previous knockout data for Prx1 (Martin et al. 1995), show that it functions to coordinate an increase in chondrocyte proliferation and hypertrophic differentiation. This suggests at least plausible mechanisms through which Prxl may interact with the skeletal regulatory network. For example, a single gain-of-function point mutation in Fgfr3 is responsible for $95 \%$ of human dwarfism, and loss of function of mouse Fgfr3 leads to increased chondrocyte proliferation and differentiation (Colvin et al. 1996; Deng et al. 1996). Mutations in the Bmp receptors Bmprla and Bmprlb result in decreased proliferation and differentiation of chondrocytes and activation of Fgfr signaling, indicating an antagonistic interaction between these two pathways (Yoon et al. 2006). Alterations to either Bmp or Fgf signaling impinge on an Ihh/Pthrp feedback loop responsible for mediating the rate of chondrocyte differentiation and for establishing the size of the growth plate.

One way that Prx1 may regulate long bone growth is by controlling Bmp2 expression in the perichondrium. Sears et al. (2006) previously showed that bat forelimb digits express higher levels of Bmp2 than do either bat hindlimbs or mouse forelimbs. This increased Bmp2 expression is localized to the perichondrium, where Cretekos et al. (2008) observe increased and prolonged Prx1 mRNA expression driven from the bat enhancer in knockin mice. The increase in Prxl expression may be directly responsible for the up-regulation of Bmp2 expression previously observed in the perichondrium, in which case the phenotypic effect of the bat Prx1 enhancer may be explained by changes in Bmp2 levels. Alternatively, independent alterations to the regulation of $B m p 2$ might be a separate evolutionarily selected change contributing, along with $\operatorname{Prx} 1$, to the overall increase in the length of the bat wing. An investigation of Bmp2 expression in bat Prx1 enhancer knockin mice will be an important first step in establishing whether $B m p 2$ and Prx1 are epistatic to one another or if they act in parallel.

\section{The fossil record and the emergence of mammalian flight}

In The Origin of Species, Charles Darwin recognized that the most serious challenge to his new theory of natural selection was its inability to explain the apparent sudden emergence of evolutionary novelty in the fossil record, and he appreciated the evolution of flight by bats to be one such problematic example (Darwin 1859). Without a series of intermediate forms to draw on, it is extremely hard to imagine how such perfected structures as the bat wing or the vertebrate eye could arise de novo via accumulation of small selected changes. This theme was developed as a central critique by perhaps the most formidable of Darwin's contemporary critics, St. George Mivart, in his major treatise, On the Genesis of Species (Mivart 1871). Indeed, the title of the chapter in which he laid out this counterargument has become the standard phrase for describing this paradox: "The Incompetency of 'Natural Selection' to Account for Incipient Stages of Useful Structures." In essence, as the argument is commonly posed: What good is $2 \%$ of a wing? In the context of the present study, this might be rephrased as: What good is elongation of the forelimb skeleton without concomitant reduction in cortical thickness of the bones, rerouted innervation, etc? Or what good is a small increase in the length of the forelimb bones when it would, 
in and of itself, be insufficient to allow powered flight? Unless these small steps had value in and of themselves, they could not have been selected.

Mounting fossil evidence indicates that the evolution of flight in birds was not sudden, but went through a series of incipient stages (for review, see Chiappe 2007). If the fossil record similarly provided intermediate forms in the evolution of Chiroptera, we might be able to appreciate the utility of the partial changes that led up to the formation of the modern bat wing as well. However, the ancestors of modern bats that first appear in the fossil record $~ 50$ million years ago during the Eocene already have elongated digits, extensive interdigital membranes, and robust anterior forelimb muscles indicative of powered flight (Thewissen and Babcock 1992; Speakman 2001; Sears et al. 2006). This has led to speculation that bat evolution occurred rapidly; however, the fragmentary fossil record is not grounds to dismiss the concept of gradual change. Indeed, recent systematic studies based on molecular and paleontological data suggest that the common ancestor of modern bats likely originated $\sim 64$ million years ago at the Cretacious/Tertiary boundary, indicating that there is at least a 14-million-year gap in the existing fossil record. Biogeographical characterization supports a theory that this ancestor was an arboreal quadruped in the Northern Hemisphere, possibly in North America (Teeling et al. 2005). Taken together, these data may allow a hypothesis-driven approach to investigate Cretaceous rocks in historically forested regions of North America to discover fossilized bat ancestors with morphologies indicative of a transition from quadrupedal to flying mammals. Such an approach has already proven successful in the identification of the tetrapodomorph Tiktaalik (Shubin et al. 2006).

\section{Summary and perspective}

While it is still unclear whether modern bats arose rapidly or gradually from their quadrupedal ancestor, it does seem certain that their evolution required many molecular changes to dramatically alter morphology from a limb to a wing. One might argue that a small and transient increase in the length of limb bones is not striking, but this is taken out of the greater context of evolution over millions of years. While on its own this specific modification to the Prx1 enhancer would not have had a dramatic effect in a more mouse-like quadrupedal ancestor, it likely contributed significantly to morphological divergence in combination with other molecular changes. Future work to identify more of these molecular changes combined with filling gaps in the fossil record will likely unravel the complicated cause and effect of bat evolution and indicate how these molecular changes may have given rise to morphological adaptation that drove bat wing evolution.

\section{Acknowledgments}

We gratefully acknowledge Sean Carroll for critical reading of the manuscript. We also thank members of the Tabin laboratory for insightful discussions. Our work is supported by NIH Grant R37 HD32443. K.L.C. is a recipient of an NRSA post-doctoral fellowship F32 HD052349.

\section{References}

Chiappe, L.M. 2007. Glorified dinosaurs: The origin and early evolution of birds. John Wiley \& Sons, New York.

Colosimo, P.F., Hosemann, K.E., Balabhadra, S., Villarreal Jr., G., Dickson, M., Grimwood, J., Schmutz, J., Myers, R.M., Schluter, D., and Kingsley, D.M. 2005. Widespread parallel evolution in sticklebacks by repeated fixation of Ectodysplasin alleles. Science 307: 1928-1933.

Colvin, J.S., Bohne, B.A., Harding, G.W., McEwen, D.G., and Ornitz, D.M. 1996. Skeletal overgrowth and deafness in mice lacking fibroblast growth factor receptor 3. Nat. Genet. 12: 390-397.

Cretekos, C.J., Wang, Y., Green, E.D., NISC Comparative Sequencing Program, Martin, J.F., Rasweiler IV, J.J., and Behringer, R.R. 2008. Regulatory divergence modifies limb length between mammals. Genes \& Dev. (this issue), doi: $10.1101 /$ gad.1620408.

Darwin, C. 1859. On the origin of species by means of natural selection, or, the preservation of favoured races in the struggle for life. John Murray, London.

Deng, C., Wynshaw-Boris, A., Zhou, F., Kuo, A., and Leder, P. 1996. Fibroblast growth factor receptor 3 is a negative regulator of bone growth. Cell 84: 911-921.

Kronenberg, H.M. 2003. Developmental regulation of the growth plate. Nature 423: 332-336.

Kronforst, M.R., Young, L.G., Kapan, D.D., McNeely, C., O'Neill, R.J., and Gilbert, L.E. 2006. Linkage of butterfly mate preference and wing color preference cue at the genomic location of wingless. Proc. Natl. Acad. Sci. 103: 65756580.

Martin, J.F. and Olson, E.N. 2000. Identification of a prx1 limb enhancer. Genesis 26: 225-229.

Martin, J.F., Bradley, A., and Olson, E.N. 1995. The paired-like homeo box gene MHox is required for early events of skeletogenesis in multiple lineages. Genes \& Dev. 9: 1237-1249.

McGregor, A.P., Orgogozo, V., Delon, I., Zanet, J., Srinivasan, D.G., Payre, F., and Stern, D.L. 2007. Morphological evolution through multiple cis-regulatory mutations at a single gene. Nature 448: 587-590.

Mivart, S.G. 1871. On the genesis of species. Macmillan, London.

Protas, M.E., Hersey, C., Kochanek, D., Zhou, Y., Wilkens, H., Jeffery, W.R., Zon, L.I., Borowsky, R., and Tabin, C.J. 2006. Genetic analysis of cavefish reveals molecular convergence in the evolution of albinism. Nat. Genet. 38: 107-111.

Sears, K.E., Behringer, R.R., Rasweiler, J.J.T., and Niswander, L.A. 2006. Development of bat flight: Morphologic and molecular evolution of bat wing digits. Proc. Natl. Acad. Sci. 103: 6581-6586.

Shapiro, M.D., Marks, M.E., Peichel, C.L., Blackman, B.K., Nereng, K.S., Jonsson, B., Schluter, D., and Kingsley, D.M. 2004. Genetic and developmental basis of evolutionary pelvic reduction in threespine sticklebacks. Nature 428: 717723.

Shubin, N.H., Daeschler, E.B., and Jenkins Jr., F.A. 2006. The pectoral fin of Tiktaalik roseae and the origin of the tetrapod limb. Nature 440: 764-771.

Speakman, J.R. 2001. The evolution of flight and echolocation in bats: Another leap in the dark. Mammal Rev. 31: 111-130.

Sucena, E., Delon, I., Jones, I., Payre, F., and Stern, D.L. 2003. 
Cooper and Tabin

Regulatory evolution of shavenbaby/ovo underlies multiple cases of morphological parallelism. Nature 424: 935-938.

Swartz, S.M., Bennett, M.B., and Carrier, D.R. 1992. Wing bone stresses in free flying bats and the evolution of skeletal design for flight. Nature 359: 726-729.

Teeling, E.C., Springer, M.S., Madsen, O., Bates, P., O'Brien, S.J., and Murphy, W.J. 2005. A molecular phylogeny for bats illuminates biogeography and the fossil record. Science 307: 580-584.

Thewissen, J.G. and Babcock, S.K. 1991. Distinctive cranial and cervical innervation of wing muscles: New evidence for bat monophyly. Science 251: 934-936.

Thewissen, J.G. and Babcock, S.K. 1992. The origin of flight in bats. BioScience 42: 340-345.

Yoon, B.S., Pogue, R., Ovchinnikov, D.A., Yoshii, I., Mishina, Y., Behringer, R.R., and Lyons, K.M. 2006. BMPs regulate multiple aspects of growth-plate chondrogenesis through opposing actions on FGF pathways. Development 133: 46674678 . 


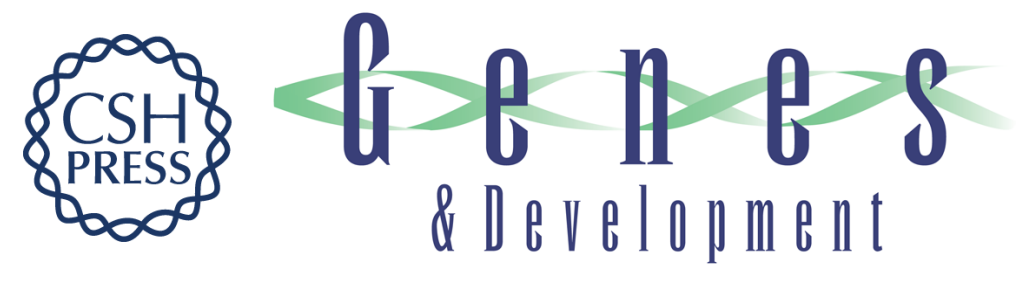

\section{Understanding of bat wing evolution takes flight}

Kimberly L. Cooper and Clifford J. Tabin

Genes Dev. 2008, 22:

Access the most recent version at doi:10.1101/gad.1639108

Related Content Regulatory divergence modifies limb length between mammals Chris J. Cretekos, Ying Wang, Eric D. Green, et al. Genes Dev. January, 2008 22: 141-151

References This article cites 19 articles, 7 of which can be accessed free at: http://genesdev.cshlp.org/content/22/2/121.full.html\#ref-list-1

Articles cited in: http://genesdev.cshlp.org/content/22/2/121.full.html\#related-urls

\section{License}

Email Alerting

Receive free email alerts when new articles cite this article - sign up in the box at the top Service right corner of the article or click here.



